\title{
ASPECTS OF LEPROSY CONTROL IN THE GAMBIA, B.W.A. (A 2-YEAR ASSESSMENT)
}

\author{
by M. J. MallaC, M.B., Ch.B. (C.T.) \\ Medical Oificer in Charge of the Leprosy Control Scheme, Gambia
}

\section{Geography}

The Gambia, oldest British possession and the smallest of the four British West African territories, is an enclave of the Senegal roughly 300 miles long and 10 miles on either side of the river Gambia. The greater part of the country is a Protectorate which is divided into four Divisions: Western, Lower River, McCarthy Island and Upper River Divisions. The main tribes are the Mandinkas or Mandingoes, the Wollofs, the Fulas, the Serahulis and the Jolas; the Mandingoes spread fairly evenly throughout the length of the territory on both banks, being specially concentrated in the Lower River Division. The Fulas preponderate in the McCarthy Island Division; the greatest concentration of the Wollofs is in the Saloum district of the Lower River Division, and the balance is spread up and down the territory on both banks, chiefly in the millet growing lands near the border, except in the Upper River Division. The Jolas are nearly all in the Western Division and most of the Serahulis live in the Upper River Division. The minor tribes are the Akus, the Bambaras, the Manjakos, the Serreres, the Jombonkos, the Mendays, the Tukulors, the Kabunkas and the Mauretanians; the overall population is 266,476 ( 1957 census).

\section{Surveys}

In 1947 Dr. C. M. Ross, Senior Specialist Leprologist of Northern Nigeria, made a sample survey in three out of the four Divisions of the Protectorate of the Gambia. He reported the incidence of leprosy to be 25 per mille and the fact that the further up river one went, the higher was the incidence of the disease.

In 1954 another sample survey was conducted by Dr. J. A. McFadzean of the Medical Research Council, Fajara, Gambia, and by Dr. J. F. McCourt, Medical Officer of Health, Gambia. Fifteen villages of the predominant tribes in the country were surveyed and the incidence of leprosy was found to be 24 per mille. Both surveys estimated the number of leprosy patients to vary between 6 and 8,000.

\section{The Leprosy Control Scheme}

Since the above two sample surveys showed that the incidence of leprosy in the Gambia was high and warranted urgent attention, WHO and UNICEF were approached in 1954 for technical assistance. In 1955 approval from UNICEF for technical assistance was obtained 


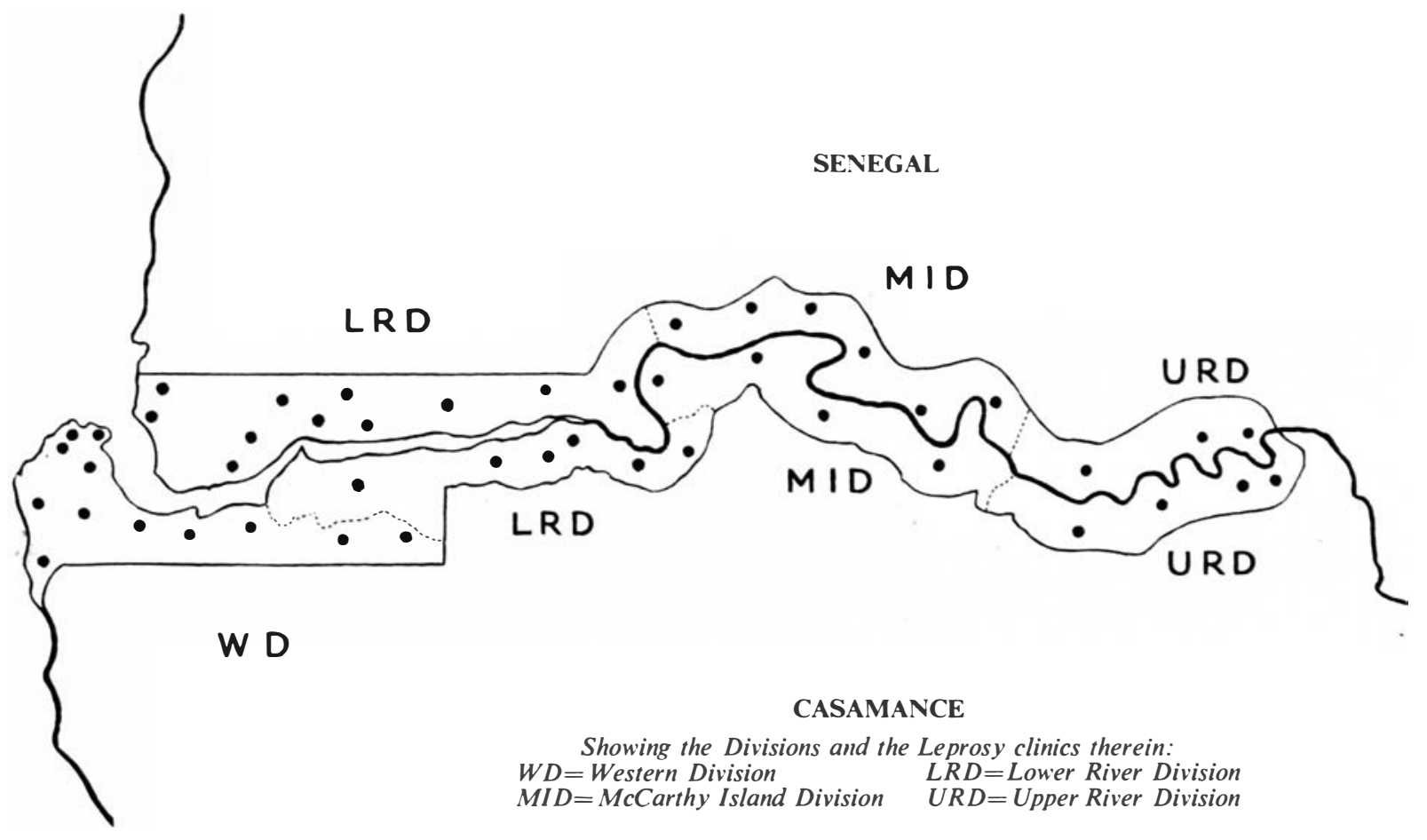


and in 1956 a Control Scheme was embodied in a Draft Plan of Operation which has currency for three years in the first place and which calls for control by means of mass out-patient treatment through the existing hospitals, health centres, dispensaries and subdispensaries. Implementation of the Control Scheme was further delayed until the recruitment of the author and in August 1957 the mass campaign was properly launched. By the middle of November, 1957, the Western Division had been covered; by the end of December the Lower River Division and by the end of February, 1958, the McCarthy Island and Upper River Divisions.

Owing to the comparatively little stigma attached to leprosy in this country, the mass campaign is carried out through the existing channel of 2 Hospitals, 7 Health Centres, 14 Dispensaries, 23 Sub-dispensaries.

This brings the total of leprosy clinics to 46 whereby each one has its own register with all particulars of each patient and the monthly attendance rate. A central register is kept at the Leprosy Field Unit H.Q's, a station more or less half way up river on the south bank of the Lower River Division.

\section{Staff}

(i) Full-time

I Medical Officer, 1 Health Inspector seconded to the Leprosy Service, 8 Assistant Leprosy Inspectors.

(ii) Part-time

24 Dresser/Dispensers, 14 Health Inspectors.

\section{Drug Used}

The tablet form of DDS on a weekly basis and up to a maximum of $600 \mathrm{mg}$.

Total Number of Villages covered: 608.

\section{Total Number of Patients}

Up to August, 1959, is 4,025 worked out as follows:

\section{Racial Significance}

$\begin{array}{lccc}\quad \text { Race } & \text { Population } & \text { No. of Patients } & \text { Incidence of Leprosy } \\ \text { Mandingoes } & 100,558 & 1,616 & 16 \text { per mille } \\ \text { Wollofs } & 42,887 & 911 & 21,, \quad, \\ \text { Fulas } & 54,073 & 678 & 12,, \quad, \\ \text { Serahulis } & 18,620 & 615 & 33,,, ", \\ \text { Jolas } & 23,909 & 159 & 6,,,,\end{array}$

The Akus, Bambaras, Manjakos, Serreres, Jombonkos, Mendays, Tukulors, Kabunkas and Mauretanians form a minority group among which are found less than 50 leprosy patients. 


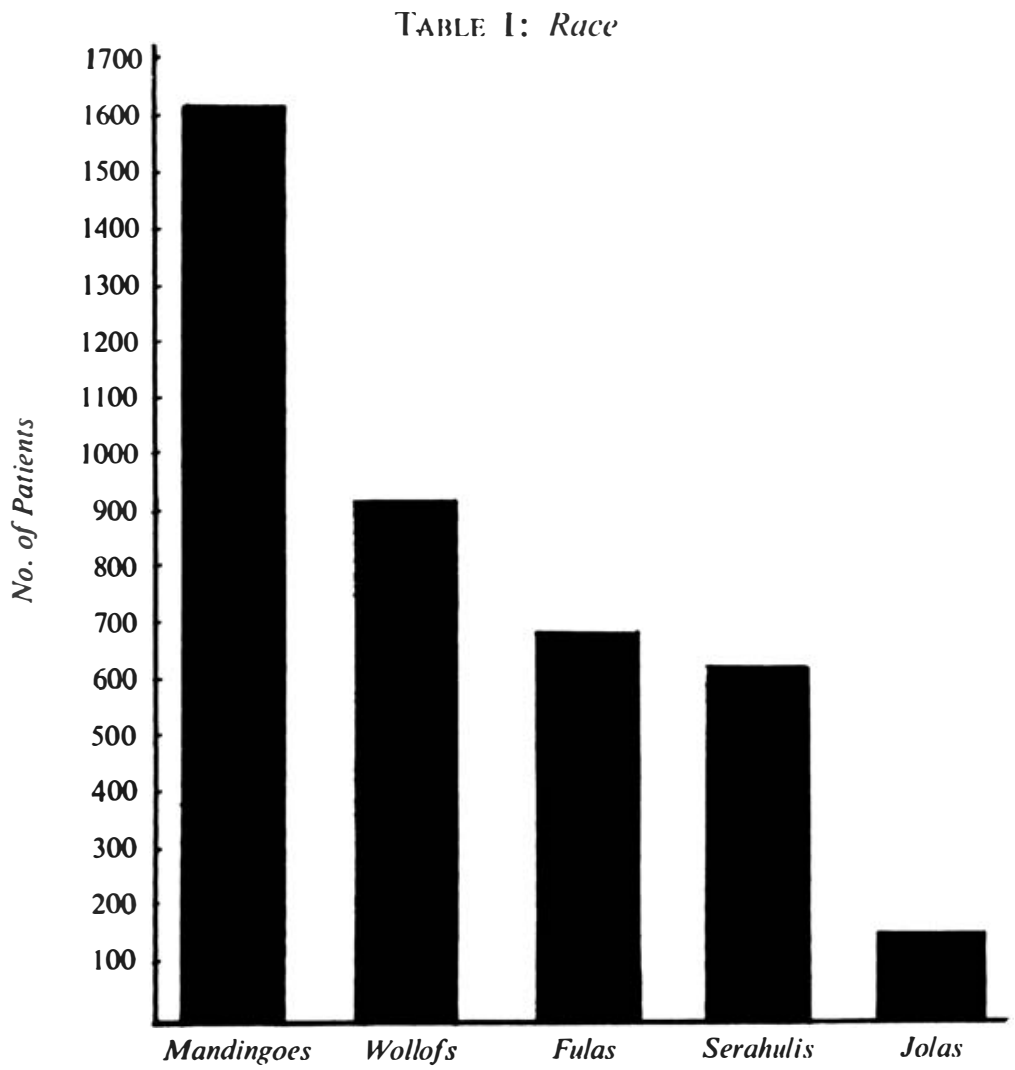

TABle II: Age Groups

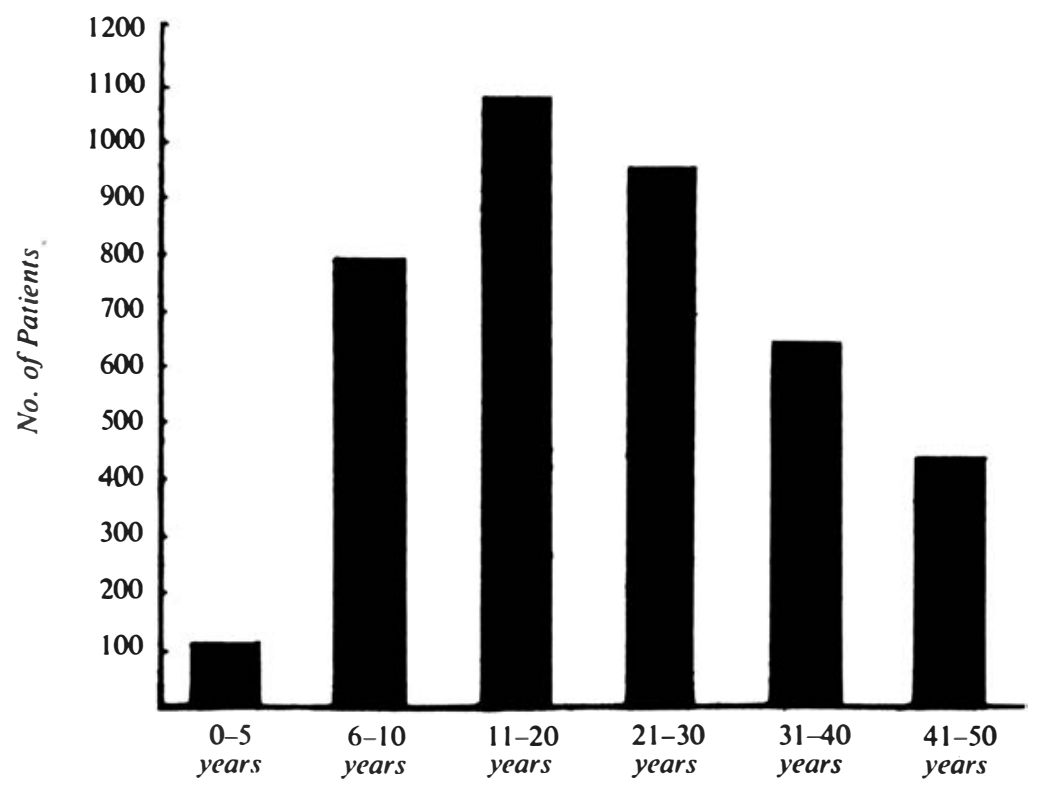


The following figures apply to the Protectorate only:
No. of Children
No. of Patients
Incidence of Leprosy
$(0-15)$
88,736
(0-15)
1,517
17 per mille
No. of Adults
No. of Patients
Incidence of Leprosy
147,685
2,508
17 per mille

Ratio Adults to Children: 5:3.

Table III: Sex

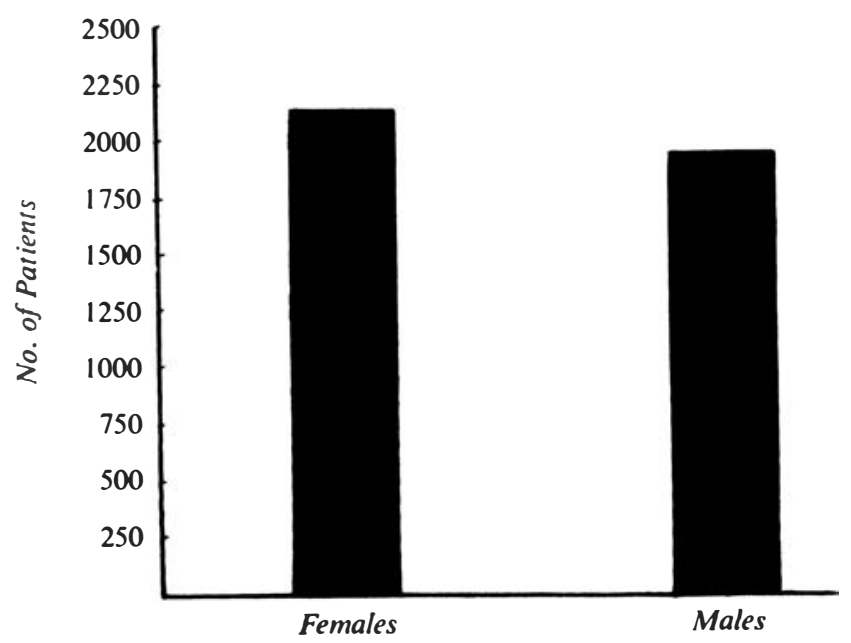

The following figures apply to the Protectorate only:

Total No. of Female Patients

2,130

Total No. of Male Patients

1,895
Population

116,210

Population

120,211
Incidence of Leprosy

18 per mille

Incidence of Leprosy

15 per mille

Since it is generally accepted that men are more affected by leprosy owing to their daily occupation outside the home, hence their greater exposure to the disease, the reverse applies so far in the Gambia since the majority of Protectorate women work all day long in the rice fields and, proportionally, harder than the men who are mostly engaged in ground-nut farming. 
TABLE IV: Types

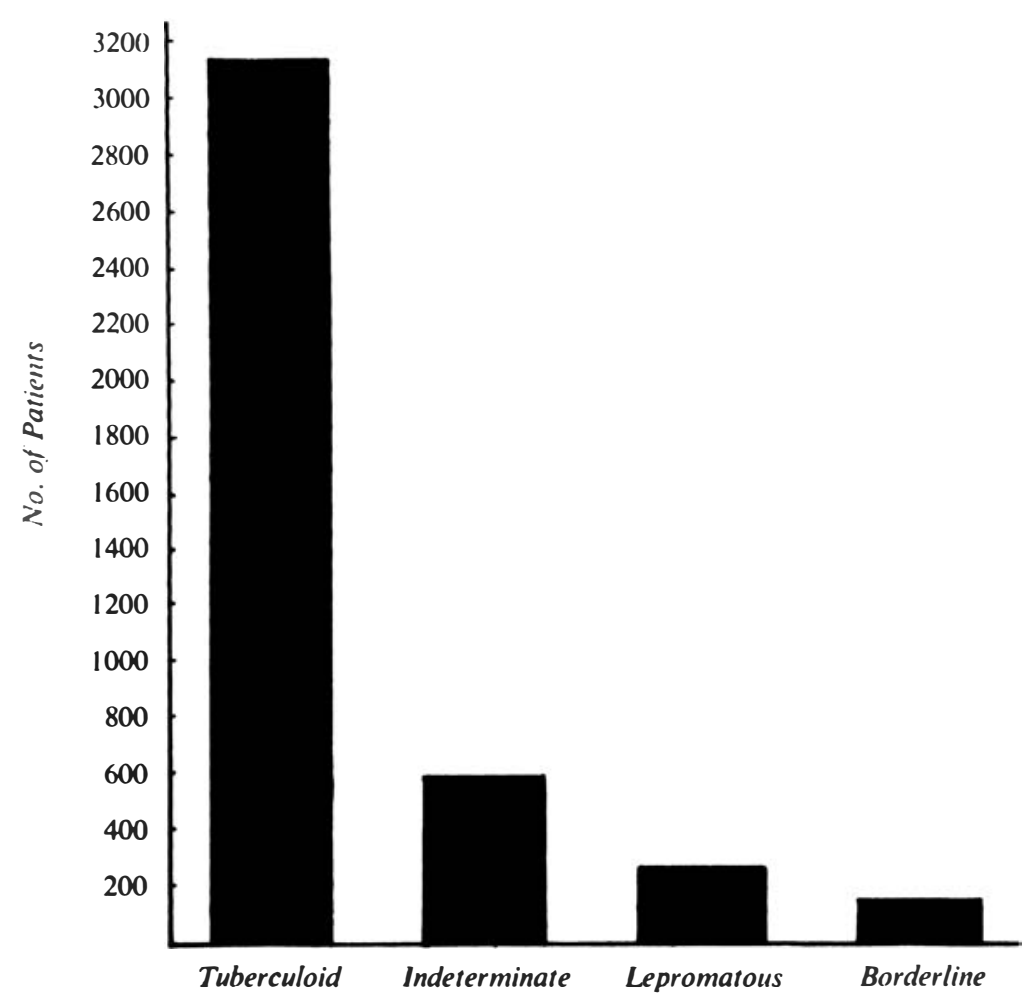

The above classification rests purely on clinical grounds and as such, in the absence of skin smears and biopsies, errors must have arisen particularly re the Borderline cases. Nevertheless, an overall picture of the various types has been obtained.

Although the predominant type in this country is so far Tuberculoid in nature, yet it comprises a very high incidence of mutilation of the extremities (an estimated 20-30\%) and of perforating ulcers of the feet (an estimated 15-20\%), a state of affairs which, no doubt, is related to the fact that for a good many years these Tuberculoid cases went on without diagnosis and treatment. Since there is no focal leprosarium so far in the Gambia and Leprosy Control is carried out on an out-patient basis only, the following steps have been taken: the patients with bad deformities of the feet are given a monthly supply of DDS at a time until they are cured from the disease; those with perforating ulcers of the feet are treated in situ and are advised, wherever possible, to walk as little as possible and are also given a monthly supply of DDS at a time until their ulcers heal up. The infected cases of ulcers are referred to the Leprosy Field Unit H.Q for admission and treatment in the Health Centre 
or, if needing X-rays and metatarsectomy, are referred to the existing two hospitals.

Of the 220 Lepromatous cases so far recorded, the distribution is as follows:

Race No. of Lepromatous Cases

Mandingoes

Wollofs

Fulas

Serahulis

Jolas
100

37

50

29

4
Incidence among Patients

62 per mille

$40,$,

73, , ,

47, , ,

$25,,$,

Ratio Male to Female: 3:2.

Ratio Adult to Child: $7: 1$.

\section{Immuno-prophylaxis with DDS}

As a preventive measure all children of the patients, from 0-5 years of age, are given a weekly dose of $25 \mathrm{mg}$. of oral DDS.

\section{Reaction to DDS}

Reactions to DDS appear to be minimal at the moment. The author has dealt personally with three cases of Erythema Nodosum Leprosum which responded very well to Fantorin. However, since Leprosy Control in this country is on an out-patient basis only and as communications are fairly bad, there must be, in his opinion, a good deal more of reactive cases which remain under cover.

\section{Discussion}

The Gambia is a small manageable country and thus there is no reason why leprosy should not be eradicated successfully. There is comparatively little stigma attached to the disease and the author found that the majority of patients lead a normal life, even when they are grossly mutilated or suffering from the Lepromatous type. Since the start of the mass campaign in August, 1957, the population at large has shown good will and co-operation and seems to realise that leprosy is a serious disease. The attendance rate varies between 40 and $60 \%$ and descends appreciably during the farming season.

However, a mass campaign on an out-patient basis only will not per se eradicate the disease for the simple reason that pill distribution will always, in the author's opinion, leave a residue of unreached patients who, by virtue of their deformities or perforating ulcers or reactions to DDS unattended to, lose heart and remain under cover, hence forming scattered reservoirs of infection. On the other hand the fact of leaving the huge bulk of deformed cases in this country uncared for is bound, apart from humanitarian reasons, to spread despondency, and prejudice the ultimate success of the campaign. 
It is therefore manifestly clear that the Gambia needs a focal leprosarium whereby the estimated $20-30 \%$ of mutilation of the extremities and the estimated $15-20 \%$ of perforating ulcers of the feet could be properly attended to as well as all the reactive cases. Lastly, apart from the fact that there is an absolute need for adequate laboratory facilities for the assessment of cured cases, new drugs could be introduced as this happens to be a time of great advance in leprosy therapy.

\section{Summary}

1. The Leprosy Control Scheme in the Gambia is two years old.

2. There are up to now 46 clinics covering 608 villages for a total of 4,025 patients.

3. Women are so far more affected than men.

4. The Lepromatous rate is so far 56 per mille and very likely much higher.

5. A focal leprosarium is badly needed.

\section{Expansion Programme}

In 1960 the Leprosy Service of this country will secure the following:

1. A lay worker or Leprosy Control Officer recruited by BELRA.

2. More Assistant Leprosy Inspectors.

3. More transport provided by UNICEF.

\section{Acknowledgement}

I am grateful to the Director of Medical Services, Dr. S. H. O. Jones, C.B.E., for kind permission to publish this paper.

\section{References}

Ross, C. M., "Report on a Sample Survey of the Gambia, 1947". Government Printer, Bathurst.

McFadzean, J. A., and McCourt, J. F., "Leprosy in the Gambia, West Africa" (April 1955) Leprosy Review, 26, 2, 57-64. 